\title{
Changing Minds? Implications of Conceptual Change for Teaching and Learning about Biological Evolution
}

\author{
Gale M. Sinatra $\cdot$ Sarah K. Brem • E. Margaret Evans
}

Published online: 12 February 2008

C) Springer Science + Business Media, LLC 2008

\begin{abstract}
Learning about biological evolution presents particular challenges for students. Barriers to learning come in the form of students' prior conceptions that conflict with the scientific perspective of biological change. Theory and research from developmental and educational psychology provide insight into these barriers. Helping students understand evolution is not simply a matter of adding to their existing knowledge, but rather, it means helping them to see the world in new and different ways. Theoretical perspectives on creating change in students' conceptions have implications for teaching about biological evolution.
\end{abstract}

Keywords Evolution education · Conceptual change · Learning $\cdot$ Teaching $\cdot$ Evolution misconceptions

The material is based upon work supported by the National Science Foundation: Grant \#0635629 to all three authors, \#0133446 to the second author, and \#0540152 to the third author.

G. M. Sinatra $(\bowtie)$

University of Nevada, Las Vegas,

4505 Maryland Parkway, Box 453003, Las Vegas, NV 89154, USA

e-mail: sinatra@unlv.nevada.edu

S. K. Brem

Arizona State University,

MC 0611,

Tempe, AZ 85287, USA

e-mail: drbrem@ml1.net

E. M. Evans

Center for Human Growth and Development,

University of Michigan,

300 N. Ingalls Bldg,

Ann Arbor, MI 48109-5406, USA

e-mail: evansem@umich.edu
The theories of evolutionary science challenge educators and learners for many reasons, not the least of which is that thinking about evolutionary processes requires us to approach the world in a different way than we do in everyday life. Research from several specialties within psychology has demonstrated that when we are faced with a new or surprising situation, we rely on some basic assumptions to simplify affairs and find a workable explanation. From infancy on, these shortcuts are extremely helpful in learning about and navigating the world most of the time; unfortunately, they do come at a cost — when we are faced with cases that do not fit our assumptions, we make errors and arrive at serious misconceptions. Evolution is one of these cases.

Our goal in this paper is to describe some of the obstacles that commonsense reasoning throws in our path when we try to think about evolution. Most of this research is in very early stages; no one has anything remotely resembling a cure-all answer to these challenges. However, perhaps we do know enough to help educators recognize seemingly odd or bullheaded thinking as clues to very powerful (and fascinating!) psychological processes that can allow us to get inside the learners' heads and better understand why they are resistant or seem unable to grasp basic concepts such as natural selection, random variation, and speciation. We will also report on how the most current research is working to develop more effective tools and curricula in the future.

The barriers to understanding evolution to be discussed here all arise because people have certain ways of looking at and thinking about the world, or, to put it another way, certain conceptions of the world. Helping people to understand evolution, then, is not a matter of adding on to their existing knowledge, but helping them to revise their previous models of the world to create an entirely new way of seeing. Psychologists refer to this type of learning as 
conceptual change. Conceptual change is necessary for some students to understand evolution, but it is also extremely difficult.

The challenges to conceptual change can be roughly divided into three categories: basic constraints that are present from infancy and early childhood, experiences that reinforce our default ways of thinking, and emotional and motivational reactions that make us reluctant to entertain the possibility of change.

\section{Developmental Constraints as a Barrier to Conceptual Change}

The term "conceptual change" is often attributed to the philosopher of science Thomas Kuhn's (1970) description of theory change in science that occurs during a paradigm shift, but psychologists often trace the notion of conceptual change to Piaget, a philosopher and biologist who is also considered the father of developmental psychology. Interestingly for us, too, his insights can be closely tied to his work as a biologist and his own studies of the interaction of genes and environment in mollusks. Childhood development, for Piaget, was a process analogous to evolution - the basic building blocks of thinking and learning provided a child with the ability to adapt to specific environmental pressures and affordances. In the case of the child, however, there is an important distinction-the actual process is not an evolutionary one, because the child is actively making choices.

Piaget provided psychologists with two important themes for understanding conceptual change. The first is the difference between assimilation and accommodation. Assimilation described the process of adding new information to knowledge structures that remained relatively unaltered. Students can come to a learning situation with little prior knowledge or with knowledge that is consistent with the new situation; learning in this case is an additive process, and relatively easy. (Of course, it can still be difficult, as any parent who has had to help their child learn multiplication or all of the state capitals can attest!) However, there are many situations where students are exposed to new ideas that directly conflict with what they already know. Piaget (1952) called the process of modifying existing knowledge structures to incorporate new information "accommodation." In these cases, altering the basic structure of their knowledge is necessary for success.

The second theme that Piaget gave psychologists was the idea that infants and children are not empty vessels that just get filled with information. We start life with default ways of making sense of the world that are biologically based; these are one set of shortcuts that allow us to learn about the world much more effectively than we would if we had to learn everything from scratch. Assimilation can occur relatively easily when the world matches with our default assumptions; accommodation is necessary when we have to move to a different way of seeing the world.

Much research has been done since Piaget, and the specifics of his underlying theory - what a child could learn when - have been substantially revised. An enduring legacy, however, is his fundamental insight that children are complex, active, and remarkably sophisticated learners. Through elegant and cleverly designed studies, developmental psychologists have since shown that even in infancy we possess several extremely powerful "rules of thumb" that shape our thinking (Wellman and Gelman 1998), and make learning about evolution very challenging, because evolution does not operate according to these rules (Evans 2000, 2001). These rules, often called "cognitive constraints" or "cognitive biases" are what we are calling the essentialist constraint, the teleological constraint, and the intentionality constraint.

The essentialist constraint Essentialism is the tendency for children to believe that things belong to categories because they have an underlying nature that we cannot see, but that gives things of that sort their basic identity (Gelman 2003). Moreover, this essence is immutable - a bird cannot become a dog, and a boy cannot become a girl. Although this essentialist tendency is most pronounced in children, we adults also tend to think this way, especially when we are pressured for time, have a lot on our minds, or encounter something unusual. It is no surprise, then, that people find evolution - changing from one kind of organism into another-highly implausible. And, even if we are willing to accept that this can happen, our minds are really not set up to think this way; wanting to see the world through the lens of evolution alone does not make it easy.

The teleological constraint Children also take the position that things are made for a purpose (Kelemen 1999). Teleology, a term attributed to Aristotle, is the attribution of design and purpose to nature and to human creations, and can be contrasted with naturalism, the philosophical stance in which science is today grounded. Children are like young Aristotles - they tend to believe that animals have eyes because they need to see, and birds have wings because they need to fly. Such thinking persists in adults, although as adults we tend to apply such explanations mostly to living things or complex artifacts (such as computers), whereas children of elementary school age can be heard to make claims such as rocks are pointy to protect themselves from being smashed by animals (Kelemen 1999).

Clearly then, children and even adults are more likely to find design-based accounts of living things much more 
plausible and in keeping with their world view than an evolutionary account.

The intentionality constraint Teleological reasoning is closely related to the intentionality constraint - the tendency to assume that events are not only purposeful but that they may be caused by an intentional agent, an agent with a "mind of its own." This makes creationist or intelligent design views very appealing and easily acquired (Evans 2000, 2001, 2008), which not only dovetails perfectly with the developmental biases of essentialism and teleology but also reinforces these intuitive cognitive biases.

Psychologists continue to debate the precise timing, course, and extent of these constraints, but it is fairly well accepted that they do exist, and that they encourage us to see our world as unchanging, orderly, and commonsensical. Children's understanding of their own and others' mental states (called theory of mind) follows a clear developmental trajectory; by 3 to 5 years of age they understand the beliefs of others can be false (Wellman and Gelman 1998) and by the middle to late elementary school years, they can reason about complex mental states such as intentions and desires with relative ease. This later capacity makes it possible to contemplate existential questions, such as how and why do living things come into existence; the kinds of questions that are at the very heart of the debate about origins (Evans 2001, 2008).

Some have even argued that naïve theories or folk theories are, in fact, evolutionary adaptations of our own (Geary 2006). According to this view, humans have evolved mechanisms that lead to successful functioning in the world, but not for learning about abstract academic domains such as quantum physics or linear algebra. Moreover, resistance to changing one's ideas is adaptive; having to reconsider every prior assumption and decision could be paralyzing and endanger one's survival. What exasperates science educators may be central to our evolutionary fitness.

\section{Prior Knowledge as a Barrier to Conceptual Change}

In addition to developmental constraints, the experiences that children have with the world further entrench their intuition, and cause them to develop particular ideas about how the world works. Both of these factors make it difficult to adopt new, more scientifically accurate ones. These intuitions, also referred to as naïve theories or framework theories, provide simple explanations for natural phenomena that work well in everyday life, even if they are not entirely accurate from a scientific standpoint (Wellman and Gelman 1998). For example, children's everyday experience of the earth is that of a flat stationary surface.
The notion of the earth being a giant ball floating in space belies this experience and requires radical restructuring. It is interesting that such restructuring often goes through shifts that involve the construction of alternative conceptions of the earth shape, or "synthetic models" (Vosniadou and Brewer 1992). For example, a child may confidently claim that there are two earths, the one we live on, which is flat and stable, and the one up in the sky that is round and in motion.

We also develop beliefs about living things, inheritance, and change through experience. The idea of framework theories in the area of biology has its roots in early work by Susan Carey (1985). Since then, Carey and others have documented a number of misconceptions that young children hold, suggesting that until a child is $8-10$ years of age, they do not have sufficient knowledge of the world to have an adequate account of concepts such as inheritance, lineage, and biological change.

Sometimes a child's misconceptions are difficult to uncover. For example, a 4- or 5-year-old knows that offspring resemble their parents, suggesting that they have a good idea of how inheritance works. However, they believe this resemblance will hold even if the child is adopted. It is not until they are 7 or 8 that they understand that some forms of parentage provide for inheritance and others do not (Solomon et al. 1996). These researchers would argue that those early developmental biases like essentialism are there, but until a child has certain knowledge - in this case, an understanding of birth (Johnson and Solomon 1997) - they think that essence can be passed by being a parent, regardless of how one came to be a parent.

As in the case of adoptive versus biological parents, some of these misconceptions tend to dissipate on their own as a child learns more about the world. But in some cases, it may be that experience consistently fails to provide the information we need to realize we are making a mistake. According to the cognitive scientist Micki Chi, this is one reason that evolution is so difficult for students to understand-we make errors, but they fit neatly with our existing understanding of the world, so we fail to see them as errors, and we are naturally reluctant to rethink our misconceptions (see also Evans 2000, 2001, 2008).

The most serious of these errors are those that require an ontological shift to fix them. Chi uses the idea of ontologies here to underscore that the shift requires a change in the nature of one's reality (Ferrari and Chi 1998). For example, we might mistake a whale for a fish; this is a misconception, but we do not have to radically change our way of looking at the world to fix it-we do have to accept that some mammals live in water, a considerable surprise, no doubt. However, our ideas about animals and fish and mammals can stay fairly much the same. 
Lateral shifts in knowledge are much more challenging. These require crossing boundaries between what Chi calls "ontologically distinct categories." A shift from thinking of something as inanimate to thinking of it as animate would be one example; others include shifting from viewing a psychological state as a physical state to recognizing it as a mental state, and shifting from seeing something as a clearly bounded event to seeing it as a process. All require radical rethinking of what we know and believe, and there is little to help us in making such a shift because our most basic assumptions and most familiar ways of thinking and talking are no longer valid. For example, it makes no sense to talk about a memory in terms of color, length, or weight as we would a physical object; discovering that a plant is a living thing requires accepting an entirely new set of assumptions, expectations, and explanations. Not only is such change difficult, it is hard for learners to even accept that such a thing is possible - it is so much easier and more sensible to retain an understanding of plants as inanimate objects, for example.

Evolution, Chi argues, is a phenomenon that requires just such a shift, making it particularly vexing to students. In particular, natural selection is an emergent process, involving a long period of time and many different, independent organisms; students, however, come to the study of evolutionary biology thinking about changes in species as an event rather than a process. An event is neatly bounded, with a clear beginning, middle, and end that can be counted on to occur in a certain order - a baseball game or a graduation ceremony are examples of events. A process is ongoing, contingent on multiple factors, and without clear start and finish. Thinking about evolution as an event causes many problems. The variation necessary for natural selection to occur does not exist in the event model, nor does differential survival and reproduction. Inheritance is an uncomplicated "handing over" of a genetic blueprint from parent to child (not unlike the handing over of a diploma!). Furthermore, change is not gradual and cumulative, but the result of a single event that completely alters the species. Not surprisingly, this event version of evolution is difficult to swallow, and if students do try to apply it, their explanations will be filled with errors.

\section{Emotion and Motivation as a Barrier to Conceptual Change}

Educational psychologists and those in the learning sciences focus on theoretical models that attempt to explain the learning process in general. Traditionally, they focused their efforts on describing cognitive mechanisms and did not address the complex of affective characteristics such as attitudes, beliefs, motives, and emotions that educational researchers observed so often in classrooms and other learning contexts. Since the revolutionary article of Pintrich et al. (1993) called for an inclusion of motivational constructs into models of conceptual change, there have been an increasing number of researchers characterizing conceptual change as social, contextual, motivational, and affective in nature (see, for example, Dole and Sinatra 1998; Gregoire 2003; Murphy and Mason 2006). There has also been more research into the ways in which learning science affects students emotionally, culturally, and personally.

For example, there have been a number of anecdotal reports that evolutionary theory is emotionally and personally unpleasant for some students to contemplate. In Unweaving the Rainbow, Richard Dawkins recounts that:

A foreign publisher of my first book confessed that he could not sleep for three nights after reading it, so troubled was he by what he saw as its cold, bleak message. Others have asked me how I can bear to get up in the mornings. A teacher from a distant country wrote to me reproachfully that a pupil had come to him in tears after reading the same book, because it had persuaded her that life was empty and purposeless. (Dawkins 1998, pg. ix)

We might not put too much stock in such anecdotes, but more systematic studies of people's beliefs about evolution are remarkably consistent with such tales. Brem et al. (2003) surveyed undergraduates regarding their perceptions of the "consequences" of believing in evolution. Would accepting evolutionary theory cause people to become more or less racist, selfish, and purposeful? Would it cause them to believe more or less in spirituality and self-determination? They were surprised to find that both students who accepted evolutionary theory and those who did not reported very similar beliefs regarding these issues; both groups thought that belief in evolution would make people more racist and selfish, less able to accept the spiritual, and reduce their sense of purpose and self-determination. Even more surprising, in a follow-up study with high school biology teachers, Griffith and Brem (2004) found that even teachers worried about such matters, and some experienced clinically measurable levels of stress when just thinking about teaching evolution. They handled their worries in various ways, but in many cases, their strategies reduced their ability to discuss evolution with students and listen to students' concerns.

Psychologists Lisa Linnenbrink-Garcia and Kevin Pugh (who is also a geologist) have been looking for ways to use affect and motivation to enhance learning about evolution (Pugh et al., under review). In particular, they are looking for what Dewey called "the transformative experience," learning that does not simply add to what a student knows, but 
enriches everyday experience and causes them to restructure those experiences. Although they have so far found transformative experiences to be rare, they have noted that a mastery orientation - the goal of learning for learning's sake-seems to be conducive to conceptual change. In addition, a sense of identity as a science student might also be helpful.

\section{Putting it All Together: Models of Conceptual Change}

One way of thinking about conceptual change is to connect the process that individual learners undergo with historical scientific revolutions - a popular approach in the 1970s and 1980s. These theorists worked from the perspective that individual conceptual change "recapitulates" the historical conceptual change that occurred within a discipline. They focused on similarities between the process of scientific revolutions as described by Kuhn (1970) and the knowledge change process as experienced by individual science learners.

One of the most influential models of conceptual change learning emerged from educators' attempts to promote "scientific revolutions" in the thinking of young learners (Posner et al. 1982; Strike and Posner 1992). Noting the strong resistance of learners to adopting scientific modes of thought even with the best efforts of instruction, Posner et al. (1982) described the conditions necessary to effect change in science students' thinking. First, learners must become dissatisfied with their existing conceptions, just as scientists must become disillusioned with their own theoretical perspective before they consider alternatives. In addition, the learner must come to see the new explanation as intelligible (easily understood), plausible (credible), and fruitful (useful for explaining other phenomena), drawing their criteria from studies of what causes scientific communities to adopt a new theory.

Beyond these more "intellectual" obstacles, students are often motivated by their belief systems and cultural identity to remain true to their current conceptions. Strong emotional and personal reactions to scientific perspectives led Strike and Posner (1992) to later revise their theory of conceptual change to acknowledge the differences between change in an individual learner and the self-correcting process of knowledge change in the scientific community. Emotions and motivation are now recognized as critical or even determinative of the likelihood of change (Sinatra and Pintrich 2003). Although such models can predict human conceptual change in some instances, they do not capture emotional attachment to a theory, fear of losing one's personal identity, or other motives for wanting to hold to one theory over another. One model, Dole and Sinatra's (1998) Cognitive Reconstruction of Knowledge Model (CRKM) can be used to illustrate the recent general trend.
The CRKM describes the learning situation as a complex interaction between the content and the learner. For example, the instructional content must be perceived by the learner as coherent, plausible, and comprehensible, as Posner et al. (1982) described. Next, the CRKM describes how the learner's existing knowledge will affect the probability that change will occur. If the learner's existing conception is coherent and deeply interconnected with other ideas they hold, the likelihood of change decreases. Change is also less likely if the learner is deeply committed to their existing point of view, even if it is not well connected to other ideas. Personal relevance of the content stemming from interest, emotional involvement, self-efficacy, and having a stake in the outcome of a dispute between two positions is also described as playing a determinative role in change. Other motivating factors include the social context; for example, students are more likely to engage with an idea if their peers show an interest.

Most important to the CRKM is the notion of the engagement continuum. Dole and Sinatra (1998) hypothesized that the low level of cognitive engagement needed to successfully complete many instructional activities requiring only superficial, surface-level processing and little reflection is not likely to result in significant conceptual change. For change to occur, the tasks must promote deep processing, elaborative strategy use and reflection.

The CRKM can be applied to understand challenges encountered by students learning about biological evolution. Specifically, if students have deeply entrenched alternative conceptions about biological "kinds" as static and immutable, they are less likely to engage with a message about the continuous gradual change in organisms evolutionary biologists describe. So, understanding the background students bring to their studies is important. If students do not view the topic of natural selection as personally relevant because the content is not connected to their personal lives, they are less likely to experience change. This fits well with the call for evolution educators to make the topic more personally relevant for students by explaining why they must take a full course of antibiotics or how ideas from evolution are used in developing treatments for diseases (see, for example, Hillis 2007). The CRKM predicts that if the instructional design of the content does not require the high engagement required by discussion, debate, argumentation, experimentation, and the juxtaposition of ideas, little change will result.

\section{What Can We Do to Foster Conceptual Change?}

First and foremost, we can appreciate that learning about a complex process like evolution, which likely conflicts with students' prior experiences, background knowledge, and 
perhaps personal beliefs, most probably requires conceptual change. As changing our conceptions is always difficult, we should expect then, that evolution will be difficult for many students to learn.

Understanding the sources of conflict and resistance to evolution and the challenges of fostering change on this topic is a next step to developing successful approaches to evolution instruction. Students come with entrenched ideas and ways of viewing the world that are in conflict with scientific perspectives such as species change, deep time, and difficult-to-observe phenomena, such as genetic drift. Conceptual change research suggests that educators must be aware of students' preconceived ideas that they bring to the classroom, and must design instruction to give students the opportunity to think deeply about alternative perspectives.

Next, there are some instructional strategies that we can adopt. At this point, they are not necessarily tested strategies, but they do address one or more aspects of the conceptual difficulties exhibited by children and adults. One strategy is to focus on the language of evolution (Evans 2008). As described earlier, children are adept at utilizing the language of mental states, and when educators and writers use intentional language they are likely to elicit this conceptual framework. By anthropomorphizing evolution, educators may succeed in arousing students' interest, but at the expense of their scientific understanding. This is especially problematic in the case of evolution, where terms such as design, need, theory, and adaptation have an everyday and a scientific meaning. Evolutionary biologists use these everyday terms in a highly specialized manner or metaphorically, but the language provides traps for the unwary. One solution is to make students aware of this conflict and to challenge them to provide examples of the intentional use of adaptation (for example) as well as its use by evolutionary biologists: Did ants adapt to their changed environment because (1) they wanted to do so and decided to change, or (2) because some ants possessed a particular trait that was advantageous in that environment? Such a strategy may have another benefit. By divorcing the language of evolution from the language of intentionality, the educator is less likely to invoke the emotions that accompany mental state explanations.

Another strategy is to connect topics in biological evolution to students' everyday experiences, such as discussing genetically modified food and antibiotic-resistant bacteria (see Hillis 2007 for example). Conceptual change research and theory suggest that students are more motivated to attend to content they see as personally relevant (Dole and Sinatra 1998). Have students try to imagine what our lives would be like without an understanding of evolution - we would be unable to develop drugs that successfully treat common childhood illness such as ear infections and strep throat, or to develop disease- or insect-resistant crops, or to breed less aggressive dogs that make good pets, etc. When evolution is connected to aspects of students' daily lives, they are more likely to see the relevance and be more motivated to work toward developing understanding of the complexities of the content.

Finally, conceptual change is more likely to occur when students can experience the phenomena directly. In class, experiments using fruit flies or cross-fertilization of plants capitalize on children's natural curiosity and allow opportunities for observations that are compelling. Conceptual change research suggests that the degree of engagement (Dole and Sinatra 1998), that is, how deeply students become involved in the content through discussion, debate, dialog, and/or experimentation, relates to the likelihood of change.

\section{References}

Brem SK, Ranney M, Schindel J. Perceived consequences of evolution: college students perceive negative personal and social impact of evolutionary theory. Sci Educ. 2003;87(2):181-206.

Carey S. Conceptual change in childhood. Cambridge, MA: MIT Press; 1985.

Dawkins R. Unweaving the rainbow: Science, delusion, and the appetite for wonder. NY: Houghton Mifflin; 1998.

Dole JA, Sinatra GM. Reconceptualizing change in the cognitive construction of knowledge. Educ Psychol. 1998;33(2/3):109-28.

Evans EM. The emergence of beliefs about the origins of species in school-age children. Merrill-Palmer Q. 2000;46:221-54.

Evans EM. Cognitive and contextual factors in the emergence of diverse belief systems: creation versus evolution. Cogn Psychol. 2001;42:217-66.

Evans EM. Conceptual change and evolutionary biology: A developmental analysis. In: Vosniadou S, editor. International handbook of research on conceptual change. New York, NY: Routledge; 2008 , in press.

Ferrari M, Chi MTH. The nature of naïve explanations of natural selection. Int J Sci Educ. 1998;20:1231-56.

Geary D. Educating the evolved mind: Conceptual foundations for an evolutionary educational psychology. In: Carlson JS, Levin JR, editors. Educating the evolved mind: Conceptual foundations for an evolutionary educational psychology. Charlotte, NC: Information Age Publishing; 2006. p. 1-99.

Gelman SA. The essential child: Origins of essentialism in everyday thought. Oxford: Oxford University Press; 2003.

Gregoire M. Is it a challenge or a threat? A dual-process model of teachers' cognition and appraisal process during conceptual change. Educ Psychol Rev. 2003;15:117-55.

Griffith JA, Brem SK. Teaching evolutionary biology: pressures, stress, and coping. J Res Sci Teach. 2004;41(8):791-809.

Hillis D. Making evolution relevant and exciting to biology students. Evolution 2007;61(6): 1261-4.

Johnson SC, Solomon G. Why dogs have puppies and cats have kittens: the role of birth in young children's understanding of biological origins. Child Dev. 1997;68(3):404-19. 
Kelemen D. Why are rocks pointy? Children's preference for teleological explanations of the natural world. Dev Psychol. 1999;35:1440-52.

Kuhn TA. The structure of scientific revolutions . 2nd ed. Chicago: University of Chicago Press; 1970.

Murphy PK, Mason L. Changing knowledge and beliefs. In: Alexander PA, Winne PH, editors. Handbook of educational psychology. Mahwah, NJ: Lawrence Erlbaum Associates; 2006. p. $305-24$.

Piaget J. The origins of intelligence in children. New York: International Universities Press; 1952.

Pintrich PR, Marx RW, Boyle RB. Beyond cold conceptual change: the role of motivational beliefs and classroom contextual factors in the process of conceptual change. Rev Educ Res. 1993;63: 167-99.

Posner GJ, Strike KA, Hewson PW, Gertzog WA. Accommodation of a scientific conception: Towards a theory of conceptual change. Sci Educ. 1982;67(4):489-508.
Pugh KJ, Linnenbrink-Garcia L, Koskey KLK, Manzey C, Stewart VC. Motivation, learning, and transformative experience: A study of deep engagement in science; (under review).

Sinatra GM, Pintrich PR. Intentional conceptual change. Mahwah, NJ: L. Erlbaum; 2003.

Solomon G, Johnson SC, Zaitchik D. Like father, like son: Young children's understanding of how and why offspring resemble their parents. Child Dev. 1996;67(1):151-71.

Strike KA, Posner GJ. A revisionist theory of conceptual change. In: Duschl RA, Hamilton R., editors. Philosophy of science, cognitive psychology, and educational theory and practice. New York: State University of New York Press; 1992. p. 147-76.

Wellman HM, Gelman SA. Knowledge acquisition in foundational domains. In: Damon W, Kuhn D, Siegler R, editors. Handbook of child psychology: Vol. 2. Cognition, perception and language. 5th ed. New York: Wiley; 1998. p. 523-74.

Vosniadou S, Brewer WF. Mental models of the earth: a study of conceptual change in childhood. Cogn Psychol. 1992;24:535-85. 